\title{
Textile Structure Reinforcement with Nanocellulose for Individual Protection Equipment
}

\author{
Diana Neto ${ }^{1 *}$ and Paula Braga Silva ${ }^{2}$ \\ ${ }^{1}$ Escola de Ciências e Tecnologia, University of Tra's-os-Montes and Alto Douro, Portugal \\ ${ }^{2}$ Escola de Ciências e Tecnologia INEGI - Institute of Science and Innovation in Mechanical Engineering and Industrial \\ Engineering, FEUP Campus, Portugal
}

*Corresponding author: Diana Neto, Escola de Cie^ncias e Tecnologia, Universidade de Tra's-os-Montes e Alto Douro, Vila Real 5000-811, Portugal

ARTICLE INFO

Received: April 04, 2020

Published: 幽 April 13, 2020

Citation: Diana N, Paula Braga S. Textile Structure Reinforcement with Nanocellulose for Individual Protection Equipment. Biomed J Sci \& Tech Res 27(1)2020. BJSTR. MS.ID.004433.

Keywords: Work Safety; Work-Related Musculoskeletal Injuries; Low Pain Back, Intelligent Textile; Nanocellulose

\section{ABSTRACT}

The occurrence of muscle injuries due, for instance, to repetitive or physically exhaustive work are increasingly common. This study aims to investigate the influence of nanocellulose impregnation on the reinforcement a textile material that has already provided good results in previous studies. The fabric impregnated with nanocellulose is an intelligent textile that will be incorporated into a t-shirt, to create new personal protective equipment (PPE), that intends to prevent and mitigate the effects of workrelated musculoskeletal injuries to the spine, namely low back pain. The correlation of the results obtained with the results from an earlier study will be fundamental for the advancement of the project.

Abbreviations: PPE: Personal Protective Equipment; NCC: Namely Cellulose Nanocrystals; NFC: Cellulose Nanofibers; BC: Bacterial Cellulose; PET: Polyethylene Terephthalate

\section{Introduction}

The lumbar spine is an anatomical structure of extreme importance because it supports a large part of the body weight, due to the displacement of the human being. In this way, it is subject to excessive wear, several types of stress and moments whish may be in the origin of different pathologies [1]. According to the report IP / 07/752 of June 4, 2007, AESST, musculoskeletal injuries are the most common work-related health problem, in Europe, affecting millions of workers with a cost of billions for employers [2]. Ranney defined (2000), work-related LMEs as a pathological state of the musculoskeletal system, resulting from the cumulative imbalance effect between the repeated mechanical stresses of work and the adaptive capabilities of the affected body region [3]. However, despite the diversity of pathologies, their symptoms are generally the same and may be associated or individualized [2]. These lesions mainly affect the dorsum-lumbar region, the cervical region and the shoulders and upper limbs. This health problem ranges from mild to severe pain and severe medical conditions that require medical treatment. In chronic cases, they can even lead to disability [2]. One of the major groups of LMEs are low back pain commonly known as "repetitive strain injury" [2].

Sex and age are factors in the development of lumbar complaints, as well as psychological factors [4,5]. The etiological factors of low back pain are several, and this is often associated with cumulative traumas that develop in individuals whose routine extends throughout the day without pauses and without knowledge of postural correction [6]. These factors are associated with the fact that preventive methods, such as job rotation or ergonomic adaptations, are not used [6]. Another interesting strategy, but little used by workers in order to minimize the functional limitations and symptomatology related to low back pain, is the use of personal protective equipment, namely the lumbar belts. Still worsening, many workers continue to carry on their activities, even presenting low back pain. Several studies have shown that low back pain varies according to the type of industry and occupation (Bigos). Despite the 
effectiveness of certain types of intervention, such as job rotation, physical activity at work, health monitoring of workers and training / sensitization of workers, these present several limitations. There is, therefore, a need to find other methods of prevention of workrelated MES that can be used during the work cycle and which are more attractive to workers.

\section{Intelligent Textile}

The intelligent materials have a coupling between mechanical and non-mechanical quantities, which gives the material a special type of behavior. In this sense, it is possible to imagine numerous applications due to the joining of fields that are not usually connected [7]. In this sense, it is possible to imagine numerous applications due to the joining of fields that are not usually connected [7]. The use of intelligent materials in the technological area attempts to explore the idea of building systems and structures with adaptive behavior that have the ability to improve properties and be repaired when necessary. This search for new solutions has added value to traditional textile substrates, guaranteeing new functionalities, either by the use of new fibers, the development of new structures, the application of new finishes or the inclusion of electronic devices [8]. The focus on product innovation, in the traditional textile industry, allowed the consolidation of an emerging area of study: that of smart textiles. This type of textile introduces a sense of change through incorporation into new products. In this way, the fabrics begin to have an active behavior instead of possessing a passive functionality [9].

By definition, an intelligent material can change its mechanical properties (shape, hardness, viscosity) or thermal, optical or electromagnetic properties, in a predictable and controlled manner, to generate a response to the surrounding environment or stimuli. These stimuli may have origin in a mechanical deformation, temperature, vapor, $\mathrm{pH}$, magnetic or electrical stimulus [10]. Nevertheless, after the textile structures manufactured, it is possible to implement complementary characteristics through finishing processes, such as hydrophilic or hydrophobic, antimicrobial or selective permeability, among others [11]. The incorporation of the "smart" feature in the textile industry can be carried out at various levels, namely at fiber level, at the coating level or adapted to an independent unit [12]. Smart textiles will tend to evolve so that the entire system is composed of textile materials, ie sensors, actuators and other materials are textiles [13]. The greatest difficulty will be to obtain a flexible, washable (water resistant), end product with good mechanical strength and electrical conductivity [14].

\section{Phase Change Textile}

Phase Change Materials (PCMs) are materials capable of changing their physical state in a certain amount of heat, absorbing the energy during the heating process and releasing it during cooling. A unique comfort effect can be obtained with this type of material used in textile materials [1]. PCMs, which are the same as paraffins, are almost all constants, while clouds are protected. And since there are PCMs, its wire temperatures are close to the normal human body temperature $\left(37^{\circ} \mathrm{C}\right)$ so they are quite useful when applied to clothing, for instance in a sweater.

\section{Nanocellulose}

Increasingly, natural polymers are being investigated as well as their properties, taking into account their sustainability. One of such materials is nanocellulose, extracted from native cellulose [15]. This material has been gaining notoriety in the textile industry due to its physical and chemical properties, as well as its availability, abundance and low cost. The fact that cellulose is considered a very interesting material to be used as reinforcement at the nano scale is due to the fact of being obtained from a renewable and biodegradable source and having chemical and mechanical properties that are appealing to various areas, such as a high Young modulus, and mechanical resistance, low density, large surface area, high surface area ratio per unit volume, low thermal expansion coefficient, high aspect ratio, associated with a low cost $[16,17]$. Celluloses are fibrous, resistant and linear homopolymers composed of D-anhydroglucopyranose units [18]. As the nanocellulose is used due to the superior chemical and mechanical properties that it possesses in relation to the cellulose, it is relevant to take into account that such properties result from the smaller amount of amorphous regions and the size of the crystals or fibers.

Thus, the nanocellulose obtained through biomass tends to be the greatest point of interest, since it does not have amorphous zones, as this is obtained by removing the amorphous zones of the cellulosic fibers. Depending on the origin, the properties of the vegetal nanocellulose vary, being able to be extracted not only through wood, but also from plants, leaves, stems or fruits and animals $[19,20]$. According to the extraction method, there are two main types of nanocellulose that can be obtained, namely cellulose nanocrystals (NCC) and cellulose nanofibres (NFC). The small size of the fibers and the crystals, together with the structure and the type of chemical bonds, make the mechanical properties of NCC and NFC ideal for use as a reinforcing phase in polymeric composites. They promote the increase of the stiffness and of elasticity modulus of the matrix phase. However, the use of NFC has advantages over NCC, in certain applications, due to its high length / width ratio, which results in a higher mechanical strength and modulus of elasticity [21]. The nanocellulose fibers can be subjected to chemical or mechanical treatments, to obtain nanocrystals and cellulose nanofibrils (CNF), or to be produced by bacteria, obtaining bacterial cellulose (BC) [15].

\section{Starch}

Starch, a white, granular is an organic chemical that is produced by all green plants. Starch is a soft, white, tasteless powder that is insoluble in cold water, alcohol, or other solvents. The basic chemical formula of the starch molecule is $\left(\mathrm{C}_{6} \mathrm{H}_{10} \mathrm{O}_{5}\right) \mathrm{n}$. It is a 
polysaccharide (q.v.) comprising glucose monomers joined in 1,4 linkages. The simplest form of starch is the linear polymer amylose; amylopectin is the branched form [22]. Starch is manufactured in the green leaves of plants from excess glucose produced during photosynthesis and serves the plant as a reservoir to food supply. Starch is stored in chloroplasts in the form of granules and in such organs as the roots of the tapioca plant; the tuber of the potato; the stem pith of sago; and the seeds of corn, wheat, and rice. When required, starch is broken down, in the presence of certain enzymes and water, into its constituent monomer glucose units, which diffuse from the cell to nourish the plant tissues.

In humans and other animals, starch is broken down into its constituent sugar molecules, which then supply energy to the tissues [22]. Most commercial starch are made from corn, although wheat, tapioca, and potato starch are also used. Commercial starch is obtained by crushing or grinding starch-containing tubers or seeds and then mixing the pulp with water; the resulting paste is freed of its remaining impurities and then dried. Aside from their basic nutritional uses, starches are used in brewing and as thickening agents in baked goods and confections. Starch is used in paper manufacturing to increase the strength of paper and is also used in the surface sizing of paper [22]. Starch is used in the manufacture of corrugated paperboard, paper bags and boxes, and gummed paper and tape. Large quantities of starch are also used in the textile industry as warp sizing, which imparts strength to the thread during weaving [22].

\section{Materials and Methods}

\section{Taffeta Fabric (Polyester)}

The textile material used was a $100 \%$ polyethylene terephthalate (PET) web mesh, one of the most commonly used thermoplastic polymers, better known by the trade name "polyester". This choice was based on previous studies that compared the morphological, chemical and mechanical characteristics of different tissues that underwent nanocellulose impregnation [1]. PET consists of polymerized units of the ethylene terephthalate monomer, with repeated units of $\left(\mathrm{C}_{10} \mathrm{H}_{8} \mathrm{O}_{4}\right)$. For the manufacture of PET, the main raw material is ethylene. It is oxidized to produce a dihydric alcohol of glycol monomer which is further combined with another monomer, terephthalic acid, at an elevated temperature in vacuum, to polymerize. The resulting polymer is cooled and cut into small pieces, which are melted and then extruded through a spinneret and the filaments are subsequently introduced into the desired polyester fiber.

After the polyester fiber created, it is transformed into a yarn, consisting of unbroken yarns of textile fibers ready to be processed into fabrics. These polyester yarns have a wide range of diameters and fiber lengths and can be made basically as a monofilament or multifilament line. The fabric was prewashed in order to eliminate all foreign substances. This also directly contains a phase change liquid material in the center of the textile fiber, since directly mixing that material with the fiber polymer increases thermoregulatory efficiency by substantially increasing the amount of PCM present therein [23]. The mechanism of operation happens through the thermoregulatory ingredient, a microcapsule, which is a material with phase change. When it comes in contact with cold environments, it solidifies by releasing heat, and when it comes into contact with a high body temperature, the capsules become liquid absorbing heat [23]. For sample preparation, twenty pieces of fabric $15 \mathrm{~mm}$ wide and $140 \mathrm{~mm}$ long are cut, these dimensions will be important for subsequent mechanical traction tests.

\section{Nanocellulose}

In the present study was used plant-based nanocellulose, since it is an abundant resource, easy to acquire and low cost, compared to other sources of production. The particle type was cellulose nanofibers, which have amorphous and crystalline regions and a percentage of approximately $100 \%$ cellulose [7]. The fibers have between $0.5 \mathrm{~m}$ to $2 \mathrm{~m}$ in length, and between $4 \mathrm{~nm}$ to $20 \mathrm{~nm}$ in width and height [7]. It was in the form of pulp, in order to facilitate the coating of textiles. The cellulose nanofibers were purchased at the University of Maine (Maine, U.S.A.) in the form of pulp, with $97 \%$ water content and 3\% fibers. The main specifications of the nanofibres used are white and odorless appearance, nominal fiber width of $50 \mathrm{~nm}$, hydrophilic and with a density of $1.6 \mathrm{~g} / \mathrm{cm}^{3}$ for the pulp form [24].

\section{Potato Starch}

Starch, a biodegradable natural polymer, can be used to form edible or biodegradable films as packaging and is considered one of the most promising biodegradable natural polymers, mainly for its availability and price. The amido consists of two fractions, the amylose (poly- -1,4-d-glucan) and amylopectin (poly--1,4d-glucan and -1,6-d-glucan). biodegradable and biocompatible, and obtained from many renewable resources. Although both fractions are composed of glucose residues, they exhibit different physicochemical properties due to their different structures [25]. Generally, amylose has stronger gelatinizing properties than amylopectin and linear amylose chains interact through hydrogen bonds than the amylopectin branched chains. The levels of amylose and amylopectin vary with the source, for example, potato starch, which is produced on a large scale throughout the world and widely used in the food industry, has on average about $20 \%$ amylose and $80 \%$ amylopectin [26,27]. The potato starch when mixed with water has a high viscosity and a good impact response, being similar to a solid material. Due to all its properties, this study used starch mixed with the nanocellulose to observe if the characteristics attributed to the textile are more advantageous than the characteristics conferred only by the nanocellulose. In this way, a gel was first made by mixing the starch with distilled water and raising its temperature to $65{ }^{\circ} \mathrm{C}$, gelling temperature of the starch. Subsequently, when a viscous gel was obtained, the nanocellulose 
was mixed. In this study, the proportion used to prepare this gel was $20 \%$ potato starch, $20 \%$ nanocellulose and $60 \%$ distilled water.

\section{Experiment}

In order to make it possible to compare the chemical, physical and mechanical properties acquired by the fabric with nanocellulose and the nanocellulose and potato starch gel, four different conditions were made for the preparation of the samples (Table 1). The textile was dipped in each of the solutions, nanocellulose in pulp and nanocellulose-starch gel for two different times $(0$ and 30 minutes). Subsequently, the samples were taken to the oven at $65 \mathrm{C}$ for five hours.

Table 1: Samples prepared.

\begin{tabular}{|c|c|c|}
\hline & Nanocellulose Polp & $\begin{array}{c}\text { Nanocellulose }+ \\
\text { Starch }\end{array}$ \\
\hline 0 min. & A1 & B1 \\
\hline $30 \mathrm{~min}$. & A2 & B2 \\
\hline
\end{tabular}

\section{Fluorescence and Ultraviolet Microscopy}

Using fluorescence and UV microscopy, it was possible to observe and analyze the surface and cross-section of the fragments and the morphological characteristics of fibers with a magnification of 800x. For this analysis the Olympus BX50 microscope with Sony CCD-IRIS camera, from the Forest Products Laboratory of the UTAD, Forestry Department, was used with the help of Professor Dr. Jose' Lousada and Mr. Armindo Teixeira [1]. Improved UV transmission close to the optical system, including the lenses and the vertical illuminator, ensures excellent brightness, sharpness and contrast for fluorescence and UV images [28]. Olympus BX50 Microscope Universal Illuminator accepts four fluorescence filter cubes that combine dichroic mirrors with barrier and excitation filters for rapid exchange between four wavelengths of fluorescence. Simultaneous observation of fluorescence and phase contrast is easily performed [28].

\section{Average Density}

Regarding the evaluation of these properties, some definitions appear that are essential for understanding the behavior of this material when subjected to certain requests. One of the important concepts that arise is that of apparent and absolute volume. The apparent (or total) volume, $\mathrm{V}$, is defined as the sum of the volume of matter and the volume of the voids contained therein [29].

$$
V=V_{r}+V_{v}
$$

where $V$ represents the apparent volume $\left(\mathrm{m}^{3}\right), \mathrm{V}_{\mathrm{r}}$ is the absolute volume $\left(\mathrm{m}^{3}\right)$ and $V_{v}$ is the volume of debris $\left(\mathrm{m}^{3}\right)$ [29]. The density $(\rho)$ was calculated by the ratio between the mass $(\mathrm{m})$ and the apparent volume (V), expressed in $\mathrm{g} / \mathrm{cm}^{3}$ [29].

$$
\rho=\frac{m}{v}
$$

For the density estimation, only one sample of each treatment was used: coating of the textile by immersion in the nanocellulose during $0 \mathrm{~min}$. and for $30 \mathrm{~min}$. (A1 and A2, respectively) and textile coating by immersion in the nanocellulose + starch mixture for 0 min. and for $30 \mathrm{~min}$. (B1 and B2, respectively). In addition to these samples, density was calculated for a standard sample (virgin fabric). The samples were weighed in an analytical balance with an accuracy of $0.001 \mathrm{~g}$ and measured (length, width and thickness). The volume was calculated considering a parallelepiped, whose dimensions were $14 \mathrm{~cm}$ long $1.5 \mathrm{~cm}$ wide, the thickness dimensions were obtained using a Nikon digital micrometer with precision $0.001 \mathrm{~mm}$ and then the density was evaluated.

\section{Water Absorption}

The test to assess the water absorption capacity provides a measure of the quantity of liquid kept inside a sample, after specific times of immersion and drainage. For this test, only one sample of each treatment was used: textile coating by immersion in the nanocellulose for $0 \mathrm{~min}$. and for $30 \mathrm{~min}$. (A1 and A2, respectively) and textile coating by immersion in the nanocellulose + starch mixture for $0 \mathrm{~min}$. and for $30 \mathrm{~min}$. (B1 and B2, respectively). In addition to these samples, the water absorption capacity for a standard sample (virgin textile) was calculated. The samples were weighed in an analytical balance with an accuracy of $0.001 \mathrm{~g}$ in an initial stage, still dry, $\left(\mathrm{m}_{0}\right)$. Later they were weighed after $15 \mathrm{~min}$, $30 \mathrm{~min}, 1 \mathrm{~h}, 2 \mathrm{~h}, 4 \mathrm{~h}, 8 \mathrm{~h}$ and $24 \mathrm{~h}$ of immersion in distilled water (m). Finally, the samples were completely dried and weighed again $\left(\mathrm{m}_{\mathrm{f}}\right.$ ). From these data, it was possible to determine the percentage of weight increase during immersion (4) and the percentage of soluble matter lost during the immersion (5) [30].

$$
\begin{aligned}
& \text { Weight gain, } \%=\frac{m-m_{0}}{m} \text {....(3) } \\
& \text { Loss soluble matter, } \%=\frac{m_{f}-m}{m} .
\end{aligned}
$$

The method used for this test was based on "International Standard D570-98, Standard Test Method for Water Absorption of Plastics" [31].

\section{Traction / Deformation}

Mechanical tensile strength tests were performed on the Instron 5848 Microtester machine from the Mechanical Testing Laboratory with the help of Professor Fa'bio Pereira. For this, 5 samples, all with the same dimensions, 140x15 mm (length and width) were evaluated. The analyzed samples were a virgin textile, one that was dipped in the nanocellulose in pulp by $0 \mathrm{~min}$ (A1), one that was dipped in the nanocellulose in pulp by $30 \mathrm{~min}$. (A2), one that was dipped in starch nanocellulose gel for $0 \mathrm{~min}$ (B1) and finally another that was dipped in the same gel for $30 \mathrm{~min}$. (B2). Then, tensile strength tests were performed at a displacement velocity of $5.5 \mathrm{~mm}$ / min. When a charge is applied to a solid, a deformation results in 
the solid. The deformation is elastic if it is completely eliminated when the load is removed. If the deformation is permanent it is called plastic [1]. The stress is the force / unit area $\sigma=F / A$ and the extension is the elongation / unit length $\varepsilon=\Delta A / A$. The stresses and elastic deformations are proportional and are related to the modulus of elasticity or Young's modulus (E) by Hooke's Law $\sigma=E / \varepsilon$. It is implicit in this equation that tensions, and extensions are axial. Note that in Hooke's law, a linear relationship between tensions and deformations, Young's modulus represents the slope of this line [1]. In this way, we will proceed to analyze the values obtained by determining the modulus of elasticity that will allow us to understand whether the sample has acquired more elasticity or not.

\section{Results and Discussion}

\section{Fluorescence and Ultraviolet Microscopy}
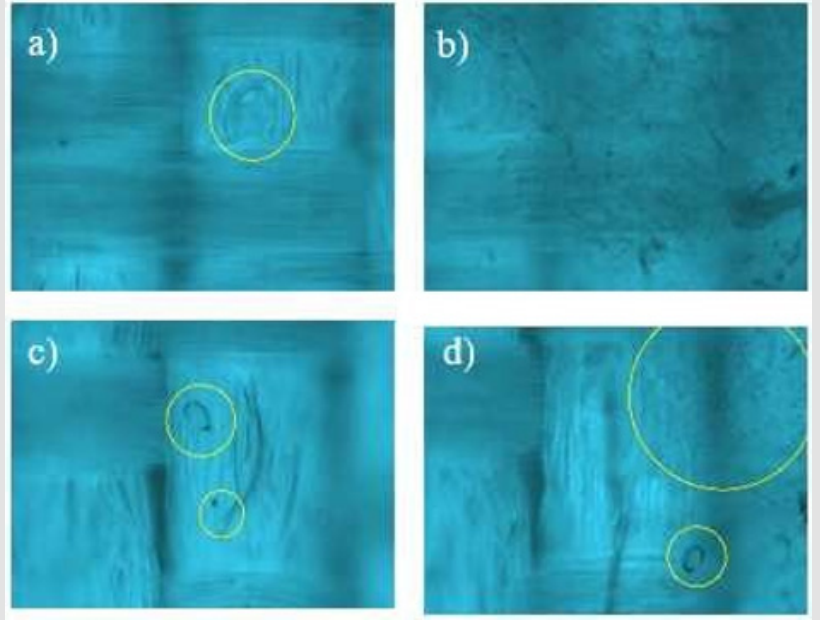

Figure 1: Images obtained with fluorescence microscopy of the samples with nanocellulose- 0 min ( $a$ and $b$ ) and nanocellulose- 30min (b and c).

Samples coated with nanocellulose and the mixture of nanocellulose and starch were observed under a microscope at a magnification of $800 \mathrm{x}$. The images were selected according to the places of interest and captured by a digital camera coupled to the microscope. In samples containing only nanocellulose there is not much difference between those that were immersed in the nanocellulose for a longer time and those that were immediately withdrawn. In addition, it should be noted that there is a trend, already mentioned in a previous study, for the existence of agglomeration zones. In this study, although it is not as evident in these images as it would be in the images obtained from a scanning electron microscope, a smooth and flat weave with approximately the same number of wires in both directions is observed and it is confirmed a break of some fibers of the fabric. By analyzing the images obtained from the samples containing the starch mixture with the nanocellulose, we can already notice an evident difference between the different dive times, and for a longer time a higher concentration of solute is observed. As in the samples with only nanocellulose, there are several agglomeration zones. In addition to these zones which prevent us from clearly seeing the weaving, many of blisters corresponding to the non-gelling starch are identified, indicating that the gellitization has not been totally completed (Figures 1 \& 2).
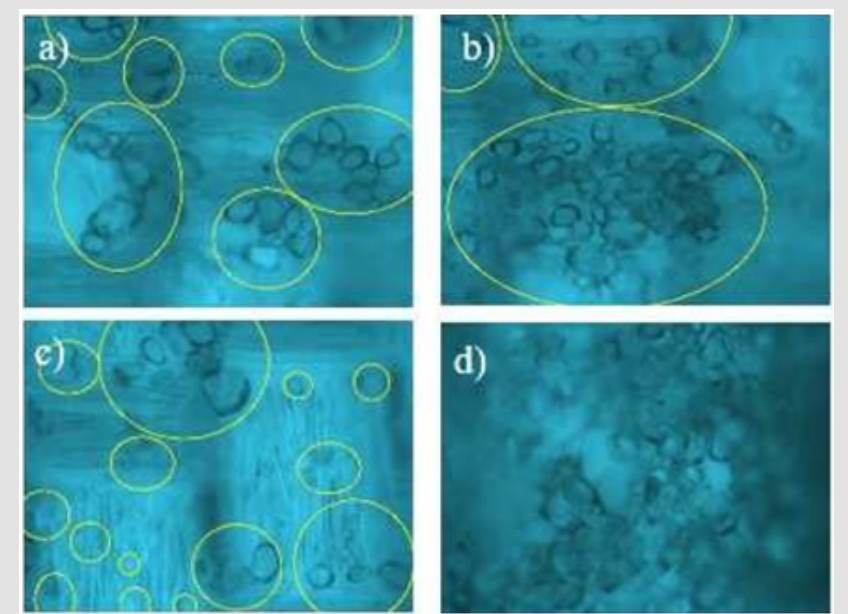

Figure 2: Images obtained with fluorescence microscopy of the samples with the mixture of nanocellulose and starch- 0min ( $a$ and b) and nanocellulose- 30min (b and c).

\section{Average Density}

To calculate the density values, data were used to estimate the sample masses, as well as their dimensions (height, length and average thickness). The results obtained for the density as well as the data are shown in the following table. Although the values are not completely accurate since these values are based on only one sample for each case and because each sample is considered a parallelepiped to determine the volume, they help to realize in general how interesting the application of the starch may be in this project (Table 2) (Figure 3). By observing the obtained results, it may be concluded that in fact the use of the starch is advantageous in this case since the samples coated with the mixture (B1 and B2) have the lowest density values.

Table 2: Density values and data.

\begin{tabular}{|c|c|c|c|c|c|}
\hline Samples & A1 & A2 & B1 & B2 & Control \\
\hline $\begin{array}{c}\text { Length } \\
(\mathrm{cm})\end{array}$ & 14 & 14 & 14 & 14 & 14 \\
\hline $\begin{array}{c}\text { Height } \\
(\mathrm{cm})\end{array}$ & 1,5 & 1,5 & 1,5 & 1,5 & 1,5 \\
\hline $\begin{array}{c}\text { Average } \\
\text { Thickness } \\
(\mathrm{cm})\end{array}$ & 0,0190 & 0,0188 & 0,0321 & 0,0938 & 0,0190 \\
\hline $\begin{array}{c}\text { Volume } \\
\left(\mathrm{cm}^{3}\right)\end{array}$ & 0,3990 & 0,3942 & 0,6735 & 1,9704 & 0,3983 \\
\hline $\begin{array}{c}\text { Weight } \\
(\mathrm{g})\end{array}$ & 0,2479 & 0,2686 & 0,3362 & 0,3694 & 0,2532 \\
\hline $\begin{array}{c}\text { Density } \\
\left(\mathrm{g} / \mathrm{cm}^{3}\right)\end{array}$ & 0,6213 & 0,6814 & 0,4992 & 0,1875 & 0,6357 \\
\hline
\end{tabular}




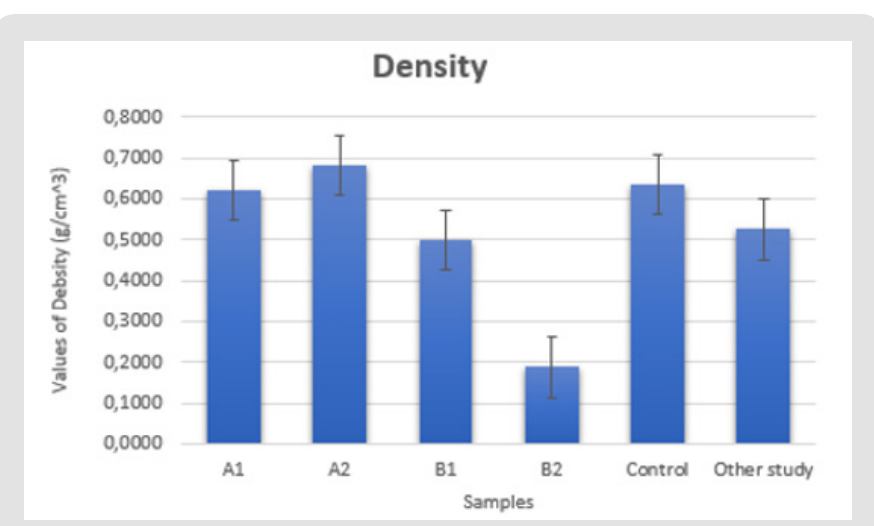

Figure 3: Density results.

\section{Water Absorption}

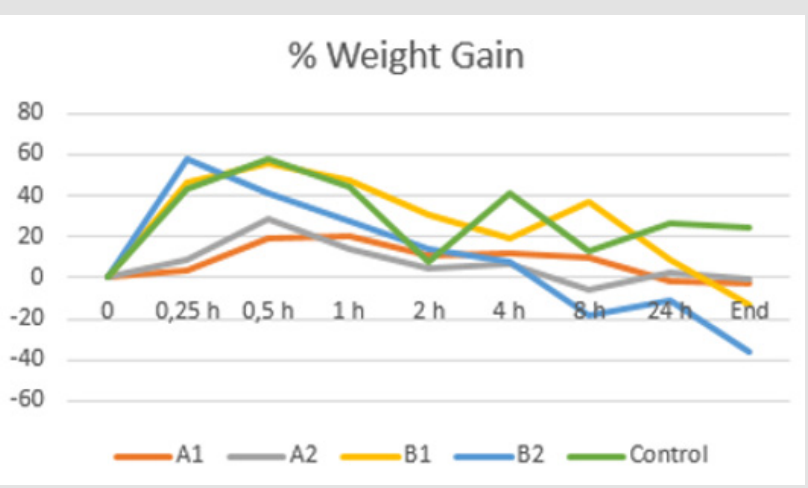

Figure 4: Percentage of weight gain.

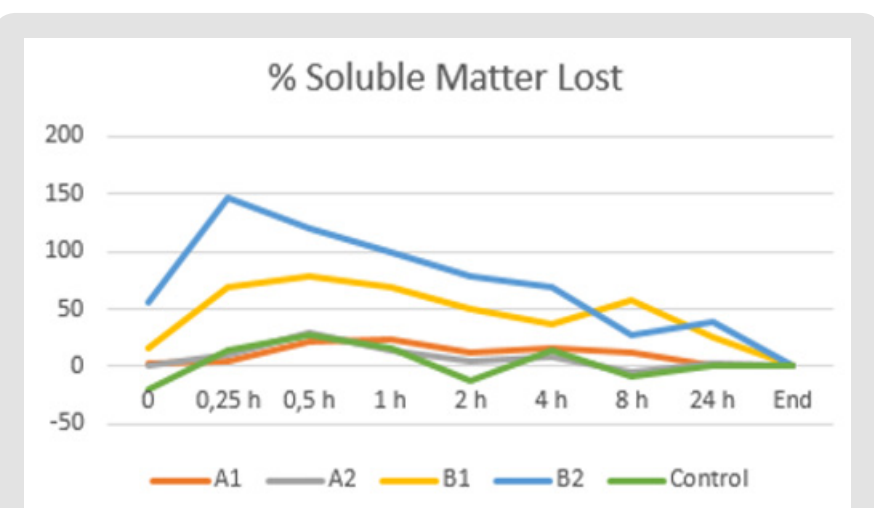

Figure 5: Percentage of soluble matter lost.

Water absorption can occur by materials in terms of "absorbed water", i.e. the amount of water absorbed from the medium. Considering the textile structures, water absorption is one of the most important mechanisms that occur during the interaction of the yarn with water. Water molecules diffuse into the amorphous regions of the wires array and break down inter-molecular hydrogen bonds. This allows an increase in the inter-molecular distance of the chains, which causes swelling. As shown in the figures below with the graphs relative to the water absorption capacity of each of the textile materials studied, in the first 15 minutes $(0.25 \mathrm{~h})$ there is high water uptake by samples containing starch and the control sample. However, starch samples also have a significant loss of soluble matter during this time. However, it is observed that the samples with nanocellulose, remain stable during the first 15 minutes (Figures 4 \& 5).

After the first analysis and observing the rest of the graph, it is verified that these results are quite inconclusive due to the imprecision of these values. This general imprecision is due to a high loss of matter on the part of all impregnated samples, which is more significant in the samples containing starch. Unfortunately, the values were also influenced by the variation of the ambient temperature and by the difference of atmospheric conditions that existed inside camera isolated from the used and external scale. During this test, it was noted that each time the samples were weighed at the end of their times, the balance was slow to stabilize indicating that the sample being weighed was losing water during weighing.

\section{Traction / Deformation}

As can be seen in the graph below, the behavior is elastic in all samples analyzed, not reaching the plastic zone. Comparing the samples, there are very significant differences, since the uncoated sample presents values of tension higher than the others $(\approx 34.02$ $\mathrm{MPa})$, for the same value of elastic deformation $(\approx 0,12 \%)$. Follow the sample impregnated with nanocellulose for $0 \mathrm{~min}$. $(\approx 33.19$ $\mathrm{MPa}$ ) and of the impregnated sample with nanocellulose for 30 $\min$. ( $\approx 29.04 \mathrm{MPa}$ ). Finally, with the lowest voltage value we have the samples impregnated with the gel, being the one that was submerged during $0 \mathrm{~min}$. has a higher stress value $(\approx 18.50 \mathrm{MPa})$ than it was for $30 \mathrm{~min}$. $(\approx 5.97 \mathrm{MPa}$ ) for the same deformation value $(\approx 0.12 \%$ ) (Figure 6).

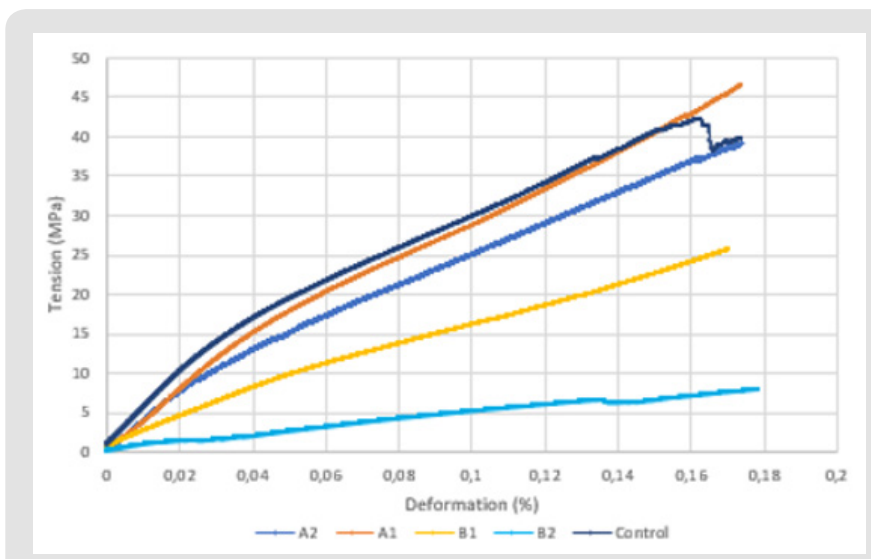

Figure 6: Traction/Deformation graph.

In the following graph we can have a better perception of the variation of the mean values of the Young's modulus of the samples. Samples with starch were found to have an average E value higher than that of samples with nanocellulose in pulp (A1 $390.42 \mathrm{MPa}$, $\mathrm{A} 2 \approx 367.74 \mathrm{MPa}$ ). Both starch and nanocellulose samples that were submerged for less time presented higher values of $E$ than those that 
were longer Thus, the lowest value $(\approx 83.67 \mathrm{MPa})$, corresponding to the sample with starch that was submerged for 30 minutes (Figure 7). In this test, it was not possible to compare the Young's modulus values obtained with the best results from the other study that have been reported since the assay conditions were different.

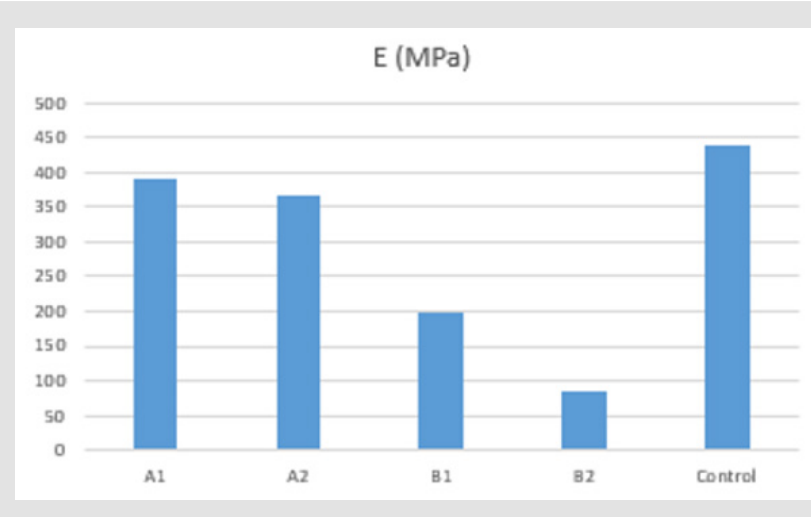

Figure 7: Results of Young's modulus.

\section{Conclusion}

1) With the microscopy, we conclude that there is a greater adhesion of the nanocellulose in the fabric, when it is mixed with the starch. Although the impregnation method of this gel has to be improved.

2) In the density tests, we verified that the less dense sample was the one that was immersed in the starch gel for a longer time. However, in the continuation of this study, the method of calculating the volume should be altered to make the results more accurate. One way to do this, could be to determine the volume through the water displacement.

3) As for water absorption tests by the samples, it was found that there is a large loss of matter on the part of all prepared samples, but more clearly those containing starch. In order to render the results more accurate, a method of attaching the gel to the fabric should be investigated so that it does not dissolve in the water. Also, the external conditions of this test would have to be meticulously controlled.

4) The traction tests proved to be the most promising because it indicated that the textile underwent a great increase in elasticity when impregnated with nanocellu- lose and starch for longer time.

\section{Acknowledgment}

The author would like to thank her friend Raquel for the support, encouragement and follow-up throughout the practical and even theoretical component. To Professor Paula, a special thank you for all the guidance, collaboration, support, understanding and concern. For UTAD (University of Tra's-os-Montes and Alto Douro) and all the people who helped in the accomplishment of this work, namely Professor Fa'bio, who assisted in everything that was requested and made a few moments of work more fun, and Dr. Jose' Lousada and Mr. Armindo Teixeira from the Building of Forestry Sciences who were willing to collaborate on this project, will be the last big thank you.

\section{References}

1. AR Sousa (2018) Development of an individual protective equipment for the prevention of low back pain. Ph.D. dissertation, UTAD: Vila Real.

2. (2007) Report ip / 07/752, Brussels: European Age for Safety and Health at Work.

3. D Ranney (2000) Work Related Crohnic Musculoskeletal Disorders. São Paulo: Editora Roca.

4. F Biering Sørensen, CE Thomsen, J Hilden (1989) Risk indicators for low back trouble. Scand Journal Rehabilitation Medicine 21(3): 151-157.

5. WS Marras (2000) Occupational low back disorder causation and control. Ergonomics 43(7): 880-902.

6. Marcelo C da Silva, Anaclaudia G Fassa, David Kriebel (2006) Musculoskeletal pain in ragpickers in a southern city in brazil. Am Journal Medicine 49(5): 327-336.

7. Marcelo Savi, Sergio A Oliveira (2013) Os materiais inteligentes e suas aplicac, $\mathrm{o}^{\mathrm{e} e s}$.

8. Orth M, Post ER (1997) Smart fabric, or "wearable clothing". Digest of Papers.

9. L Berglin (2005) Smart textiles - what for and why. Textile Journal.

10. YK Wen (1992) Intelligent structures 2: Monitoring and control. Elsevier.

11. H.C.C.M.P.R.E.H.v.M.D. Langenhove LV (2003) The use of textile electrodes in a hospital environment," Ph.D. dissertation. Technical University of Lodz, Poland.

12.X Tao (2001) Smart fibres, fabrics, and clothing. $1^{\text {st }}$ (Edi.), Woodhead Publishing, UK.

13. D De Rossi, A Della Santa, A Mazzoldi (1999) Dressware: wearable hardware. Materials Science and Engineering: C 7(1): 31-35.

14. Alexandre F, Fernando Nunes F, Fernando Ribeiro o (2014) Te^xteis inteligentes - uma breve revisa o da literature. REDIGE 5(1).

15. Dufresne A, Lin N (2014) Nanocellulose in biomedicine: Current status and future prospect. European Polymer Journal 59: 302-325.

16. Anand PM, John S, Albert SB (2009) Cellulose/DNA hybrid nanomaterials. Biomacromolecules 10(3): 497-504.

17. Lee SH, Teramoto Y, Endo T (2011) Cellulose nanofiber-reinforced cellulose polycaprolactone/polypropylene hybrid nanocomposite. Composites Part A-Applied Science and Manufacturing 42(2): 151-156.

18. Foster EJ, Jorfi M (2015) Recent advances in nanocellulose for biomedical applications. Journal of Applied Polymer Science 132(14).

19. Leitner J, Hinterstoisser B, Wastyn M, Keckes J, Gindl W (2007) Sugar beet cellulose nanofibril-reinforced composites. Cellulose 14: 419-425.

20. Kalia S, Dufresne A, Cherian BM, Kaith BS, Avérous L, et al. (2011) Cellulose-based bio- and nanocomposites: A review. International Journal of Polymer Science 2011: 837875.

21. Khalil HPSA, Bhat AH, Yusra AFI (2012) Green composites from sustainable cellulose nanofibrils: A review. Carbohydrate Polymers 87(2): 963-979.

22. (2018) Starch.

23. A Gerschenfeld (2015) 0 estranho mundo novo dos têxteis high-tech. Nanotecnologia.

24. Moon RJ, Martini A, Nairn J, Simonsen J, Youngblood F (2011) Cellulose nanomaterials review: structure, properties and nanocomposites. Chem Soc Rev 7. 
25. TA Pereira (2018) Development of a biocomposite reinforced with nanocellulose. Ph.D. dissertation, UTAD: Vila Real.

26. Brito LM, Tavares MIB (2013) Desenvolvimento de nanocompósitos à base de amido de batata. Polımeros 23(6).

27. Wang K, Wang W, Ye R, Liu A, Xiao J, et al. (2017) Mechanical properties and solubility in water of corn starch-Collagen composite films: Effect of starch type and concentrations. Food Chemistry 216: 209-216.

ISSN: 2574-1241

DOI: 10.26717/BJSTR.2020.27.004433

Diana Neto. Biomed J Sci \& Tech Res

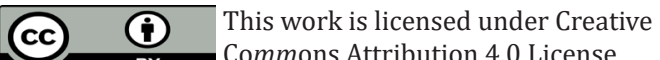

Submission Link: https://biomedres.us/submit-manuscript.php
28. JG McHone (2018) Olympus bx50/bx40.

29. DF Silva (2018) Mechanical and theoretical characterization of a fungibased biocomposite. Ph.D. dissertation, UTAD: Vila Real.

30. (2000) Textiles - test methods for nonwovens-Part 6: Absorption. Tech Rep ISO 9073-6: 2000.

31. (2010) Standard test method for water absorption of plastics.

https://biomedres.us/ 